\title{
A Novel Radio Frequency Identification (RFID)- Based Thermal Convection Nonfloating-Type Accelerometer with Stacking Layers under Heater and Thermal Sensors
}

\author{
Jium-Ming Lin*, Cheng-Hung Lin ${ }^{1}$, Meng-Hsuan Yang ${ }^{2}$ and Chia-Hsien Lin ${ }^{3}$ \\ Department of Electronic Engineering, Chung-Hua University, \\ 707, Sec. 2, Wu-Fu Rd., Hsin-chu 30012, Taiwan \\ ${ }^{1}$ Engineering Science, College of Engineering, Chung-Hua University, \\ 707, Sec. 2, Wu-Fu Rd., Hsin-chu 30012, Taiwan \\ ${ }^{2}$ Graduate Institute of Mechanical Engineering, Chung-Hua University, \\ 707, Sec. 2, Wu-Fu Rd., Hsin-chu 30012, Taiwan \\ ${ }^{3}$ Graduate Institute of Electrical Engineering, Chung-Hua University, \\ 707, Sec. 2, Wu-Fu Rd., Hsin-chu 30012, Taiwan
}

(Received July 2, 2014; accepted March 23, 2015)

Key words: radio frequency identification (RFID), thermal convection, nonfloating type, accelerometer, stacking material

In this research, we propose a wireless nonfloating-type thermal convection accelerometer. The heaters and thermal sensors of the accelerometer were made on a flexible substrate with a stacking layer (aluminum nitride of $1 \mathrm{~mm}$ thickness), and it is different from traditional structures with a grooved chamber in the silicon substrate. Thus, one can integrate it and a wireless radio frequency identification (RFID) antenna on the same substrate, making it easy for fabrication and use. Moreover, xenon gas was applied to avoid the oxidizing effect produced by the previous ones with $\mathrm{CO}_{2}$ or air to increase the heater's reliability and life cycle. The performances of a traditional rectangular chamber with xenon or $\mathrm{CO}_{2}$ without a stacking layer had nonlinear effects. However, the cases with a stacking layer and xenon gas are always better. Both sensitivity and response time comparisons with a rectangular chamber, a stacking material, and filled by $\mathrm{CO}_{2}$ were also made (sensitivity: $0.182{ }^{\circ} \mathrm{C} / \mathrm{G}$ ); the sensitivity of the new one with a hemicylindrical chamber, xenon gas, and stacking layer was better $(0.227$ ${ }^{\circ} \mathrm{C} / \mathrm{G}$ ) and without a nonlinear effect in larger accelerations. Besides, the response times using either the hemicylindrical chamber and/or xenon gas were faster than those with the rectangular chamber and $\mathrm{CO}_{2}(600 \mu \mathrm{s})$. The quickest one is $310 \mu \mathrm{s}$ by applying the proposed ideas.

*Corresponding author: e-mail: jmlin@chu.edu.tw 


\section{Introduction}

Conventional thermal convection accelerometers are manufactured on silicon wafers, ${ }^{(1-4)}$ and the device chamber is filled with any gas, such as nitrogen, argon, $\mathrm{SF}_{6}, \mathrm{C}_{2} \mathrm{~F}_{6}, \mathrm{C}_{3} \mathrm{~F}_{8}$, $\mathrm{C}_{4} \mathrm{~F}_{8}$, air, and $\mathrm{CO}_{2} \cdot{ }^{(5)}$ However, the fluoride gases may be decomposed by heating and are not environmentally friendly. The substrate was a bare silicon coated by a layer of the polyimide PI-2611, and the device was made on the polyimide to prevent power leakage through the previous silicon substrate. ${ }^{(6-9)}$ On the other hand, either air or $\mathrm{CO}_{2}$ contains oxygen, which may oxidize the heaters and reduce their lifespan. ${ }^{(10)}$ The objective of this study is to integrate a thermal-convection-type accelerometer ${ }^{(11)}$ and a wireless RFID antenna on the same flexible substrate (such as plastic or PI film), as shown in Fig. 1. Thus, it is very convenient for fabrication and usage, and the energy loss by the traditional silicon substrate can be reduced. ${ }^{(12)}$ Since the thermal conductivity of the flexible substrate such as polyimide $[0.06-0.0017 \mathrm{~W} /(\mathrm{cm} \cdot \mathrm{K})]$ is about twenty-fifth that of silicon $[1.48 \mathrm{~W} /(\mathrm{cm} \cdot \mathrm{K})]$, the flexible substrate can prevent more power leakage from the flexible substrate.

The sensitivity of an inclinometer can be increased by using a nonfloating structure on a flexible substrate without a grooved cavity, such as the conventional silicon-based device. ${ }^{(13-15)}$ Besides, both the heater and thermal sensors were made by evaporation and stacked on a material such as aluminum nitride (of $1 \mathrm{~mm}$ thickness). Moreover, the chamber was filled with an inert gas such as xenon to avoid the oxidizing effect produced by the previous ones with carbon dioxide or air. ${ }^{(16,17)}$ Thus, not only the heater but the device reliability and life cycle could be improved. Moreover, the inner shape of the chamber was hemicylindrical, which could make the sensitivity larger than that of the traditional device with a rectangular package. ${ }^{(18)}$ On the other hand, the package's outer shape can still apply the rectangular type to easily mark the part and series numbers. Thus, in this work, we applied these new ideas to fabricate a thermal convection accelerometer. ${ }^{(19)}$ It was found that the performances by using the traditional

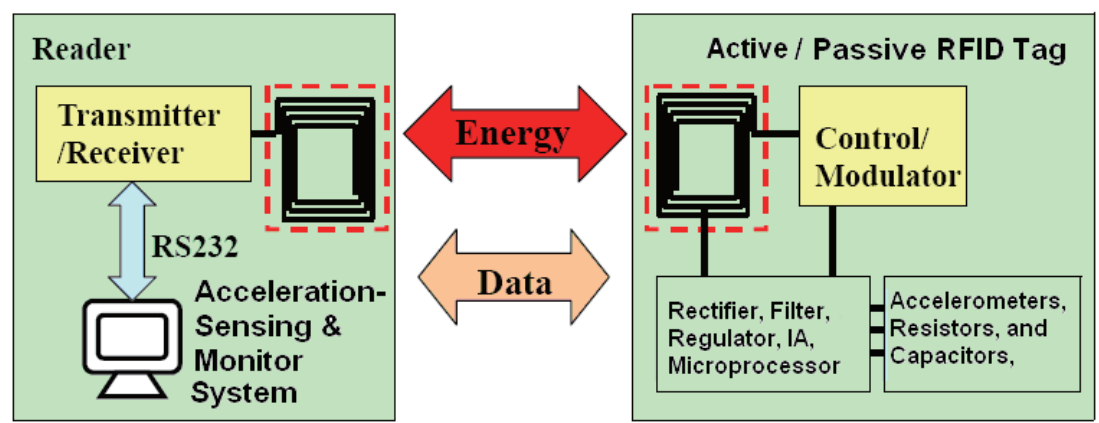

Fig. 1. (Color online) Block diagram of the new device. 
rectangular chamber for either xenon or $\mathrm{CO}_{2}$ without a stacking layer had nonlinear effects. However, the cases by using a stacking layer and xenon gas are always better. Comparisons with the previous accelerometer with a rectangular chamber, a stacking layer, and filled by $\mathrm{CO}_{2}$ were also made; the sensitivity was $0.182{ }^{\circ} \mathrm{C} / \mathrm{G}$ (in which $\mathrm{G}$ stands for $9.8 \mathrm{~m} / \mathrm{s}^{2}$ ). Moreover, the sensitivity for the new one with the hemicylindrical chamber, xenon gas, and stacking layer is better $\left(0.227^{\circ} \mathrm{C} / \mathrm{G}\right)$ and without nonlinear effects in larger accelerations. The new device can be used in the applications of air bags and the munition industry. ${ }^{(20,21)}$ Besides, the response times by using either the hemicylindrical chamber and/or xenon gas were faster than the conventional one with the rectangular chamber and $\mathrm{CO}_{2}(600 \mu \mathrm{s})$. The fastest one is $310 \mu$ s for the case applying all the proposed ideas. Moreover, they are also faster than those of the floating cases.

This paper is organized as follows: the first section is the introduction. The second one concerns fabrication and packaging steps. The third one is simulation results and discussion. The last part is the conclusion.

\section{Fabrication and Packaging Steps}

Step 1: Deposit $\mathrm{SiO}_{2}$ on both sides of the substrate for thermal, electrical, and humidity isolation. Then, cover the photoresist (PR) to protect the layers of $\mathrm{SiO}_{2}$.

Step 2: Deposit aluminum nitride (with a thickness of $1 \mathrm{~mm}$ as a stacking layer to improve sensitivity) on the substrate. Cover the PR on the front side. Using mask \#1 and PAEP, the PR on the cavity is retained to protect the underlying aluminum nitride. Remove the layer of aluminum nitride not covered by the PR. The result is as shown in Fig. 2.

Step 3: Remove the PR on the surface. Evaporate p-type amorphous silicon with a thickness of 100-250 $\mu \mathrm{m}$, then use an Nd-YAG laser to anneal it as a polysilicon thermister. Next, cover a layer of PR on the front side. Using mask \#2 and PAEP, the $\mathrm{PR}$ on the thermister is allowed to remain to protect the underlying layer of polysilicon. The next is to use KOH solution or RIE to remove the polysilicon without PR protection. Remove the PR. Evaporate $\mathrm{Cr}$ and $\mathrm{Ni}$ to be used as heater, RFID antenna, as well as the conductors connected to the power supply. The next is to use mask \#3 and PAEP to reserve the PR on the heater, RFID antenna, and the conductors connected to the power supply. Use sulfuric acid solution to remove the layers of $\mathrm{Cr}$ and $\mathrm{Ni}$ without $\mathrm{PR}$ protection. Remove the PR; the result is as shown in Fig. 3.
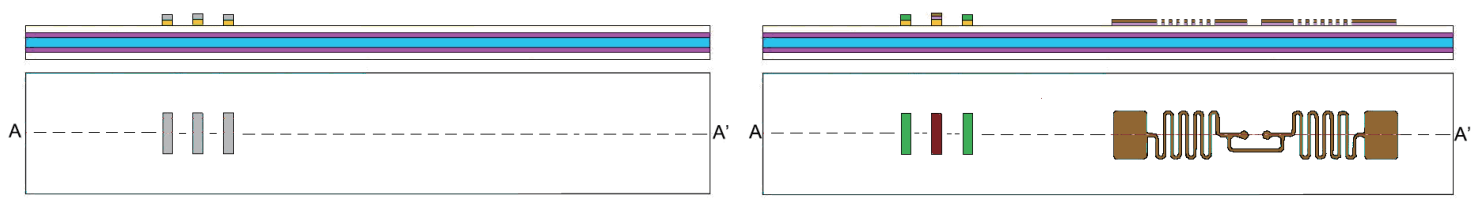

Fig. 2 (left). (Color online) Result of Step 2.

Fig. 3 (right). (Color online) Result of Step 3. 
Step 4: Use mask \#4 and PAEP to reserve the PR on the heater, and then flash a layer of gold on the $\mathrm{Ni}$ layer by electroless plating to improve the conductivity of the RFID antenna, as well as the conductors connected to the power supply. Moreover, the performance of the soldering process on the pads for packaging could be increased.

Step 5: Print a plastic or polymer material around the accelerometer as a dam bar, then put a cap on the dam bar, followed by curing; before sealing, one can fill the device chamber with carbon dioxide or xenon gas. Finally, the chip with metal bumps is flipchip-bonded to the antenna feed terminal. Then, make the underfill to raise the chip adherence; the result is as shown in Fig. 4.

\section{Simulation and Discussion}

ESI-CFD + software is used for simulation. Let the thicknesses of aluminum nitride, thermisters, and heater be $1(T 1), 0.3(T 2)$, and $0.3(T 3) \mathrm{mm}$, respectively. The components are equally spaced $(S=6 \mathrm{~mm})$. The geometries of the hemicylindrical and rectangular chambers for the floating and nonfloating structures are respectively defined in Figs. 5 and 6, in which $H=18.7 \mathrm{~mm}$; the widths of aluminum nitride, thermisters, and heater are the same as $W 1=4 \mathrm{~mm}$. Moreover, the temperatures of the package boundaries and heater are respectively set as 300 and $400 \mathrm{~K}^{(22-32)}$

\subsection{Floating structure}

The sensitivity curves by using the hemicylindrical and rectangular chambers filled with $\mathrm{CO}_{2}$ and xenon gases are as shown in Figs. 7(a) and 7(b), respectively. Note from Fig. 7(a) that the sensitivity by using the rectangular chamber with $\mathrm{CO}_{2}$ is better at lower acceleration but degrades above $18 \mathrm{Gs}\left(1 \mathrm{G}=9.8 \mathrm{~m} / \mathrm{s}^{2}\right)$. Moreover, it is even lower than that with xenon for accelerations larger than 28 Gs. Note also from Fig. 7(b) that the

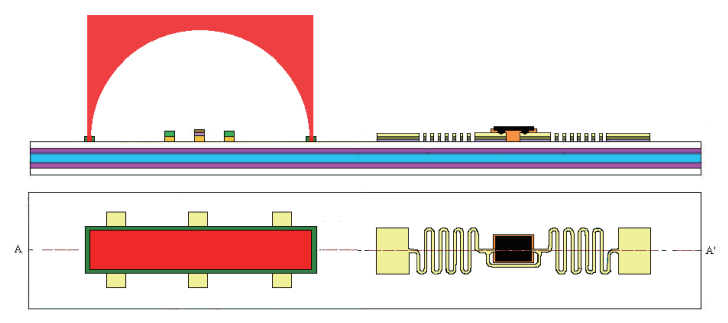

Fig. 4. (Color online) Result of the nonfloating structure.

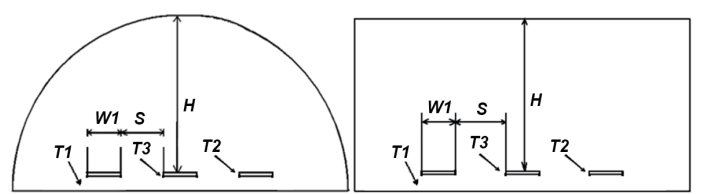

(a)

(b)

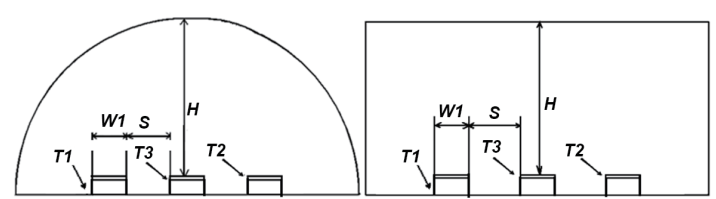

(a)

(b)

Fig. 5 (left). Geometries of (a) hemicylindrical and (b) rectangular chambers by using floating structure.

Fig. 6 (right). Geometries of (a) hemicylindrical and (b) rectangular chambers by using nonfloating structure. 


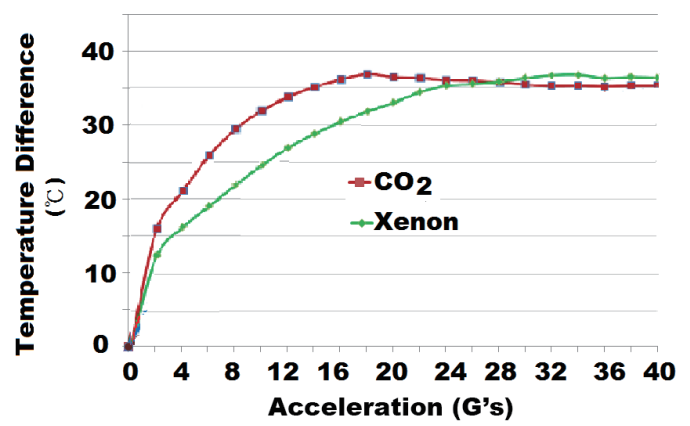

(a)

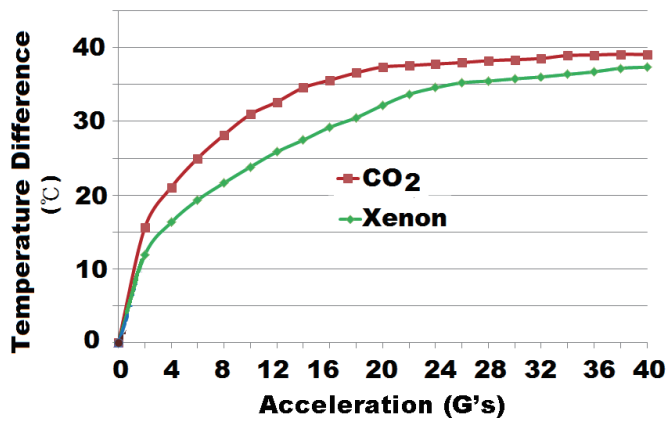

(b)

Fig. 7. (Color online) Sensitivity curves for cases applying floating structure and filled with $\mathrm{CO}_{2}$ and xenon gases. (a) Rectangular chamber. (b) Hemicylindrical chamber.

sensitivity by using the hemicylindrical chamber with $\mathrm{CO}_{2}$ is better at lower Gs, and the performance will not degrade at higher Gs. Moreover, the linearity of the sensitivities by using xenon is better than that using $\mathrm{CO}_{2}$ for accelerations from 4-24 Gs.

The next is to study the response times (with $32 \mathrm{G}$ step-input acceleration) of gas total energy and velocity by using the rectangular and hemicylindrical chambers with $\mathrm{CO}_{2}$ and xenon gas; the results are respectively shown in Figs. 8-11 and listed in Table 1 for comparison. Note that the responses by using either the hemicylindrical chamber and/or xenon gas are faster than the conventional one with the rectangular chamber and $\mathrm{CO}_{2}(910 \mu \mathrm{s})$. The quickest one is $500 \mu \mathrm{s}$ for the case applying the proposed ideas by using the hemicylindrical chamber and xenon gas.

\subsection{Nonfloating structure}

The sensitivity curves of the hemicylindrical and rectangular chambers with/without a stacking layer by using $\mathrm{CO}_{2}$ and xenon gas are as shown in Figs. 12 and 13. Note from Fig. 12 that the sensitivities by using the stacking layer and/or xenon gas are better. On the other hand, Figs. 14(a) and 14(b) show the sensitivity curves by using rectangular and hemicylindrical chambers filled by $\mathrm{CO}_{2}$ and xenon gas for the cases with/without the stacking layer, respectively. Note that the device performances by using the traditional rectangular chamber for either gases without the stacking layer had nonlinear effects. However, the case of applying the hemicylindrical chamber and filled by xenon gas with a stacking layer is more linear and better, such as $0.227^{\circ} \mathrm{C} / \mathrm{G}$ as listed in Table 2. Thus, the proposed device can be used under larger acceleration conditions, such as air bags and weapon systems of the munition industry.

Moreover, the step-input acceleration (32 G) response times of gas total energy and velocity for the rectangular and hemicylindrical chambers using stacking layer with $\mathrm{CO}_{2}$ and xenon are respectively shown in Figs. 15-18 and also listed in Table 3 for comparison. Note that for the nonfloating structure, the response times by using either the hemicylindrical chamber and/or xenon gas are also faster than the conventional one with the rectangular chamber and $\mathrm{CO}_{2}(600 \mu \mathrm{s})$. The quickest one is $310 \mu \mathrm{s}$ for the case applying the proposed ideas by using the hemicylindrical chamber and xenon gas. Moreover, they are also faster than those devices of the floating cases as listed in Table 1. 


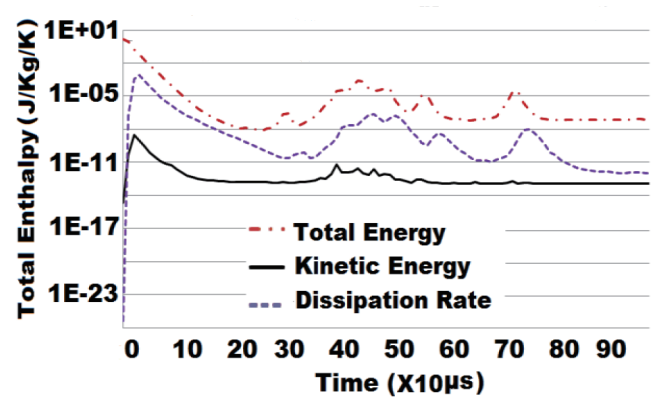

(a)

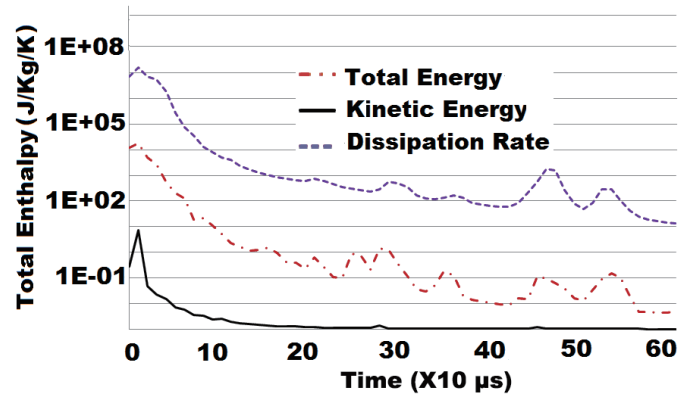

(b)

Fig. 8. (Color online) Gas total energy responses of step-input acceleration for cases applying floating structure and rectangular chamber with (a) $\mathrm{CO}_{2}$ and (b) xenon.

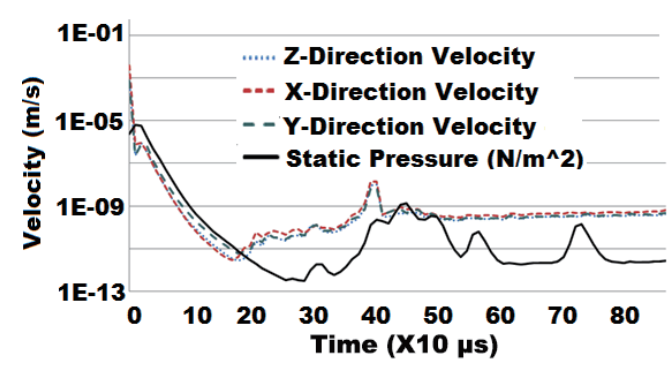

(a)

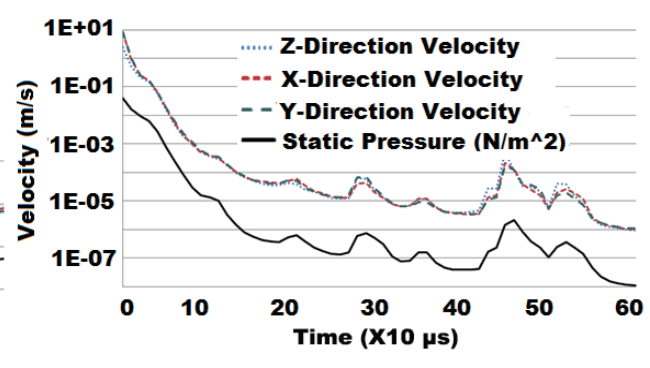

(b)

Fig. 9. (Color online) Gas velocity responses of step-input acceleration for cases applying floating structure and rectangular chamber with (a) $\mathrm{CO}_{2}$ and (b) xenon.

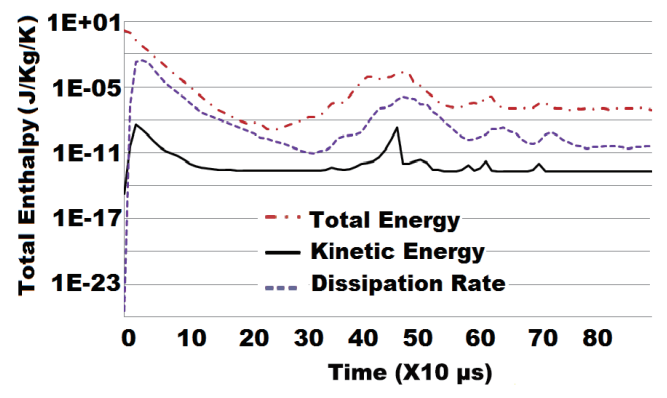

(a)

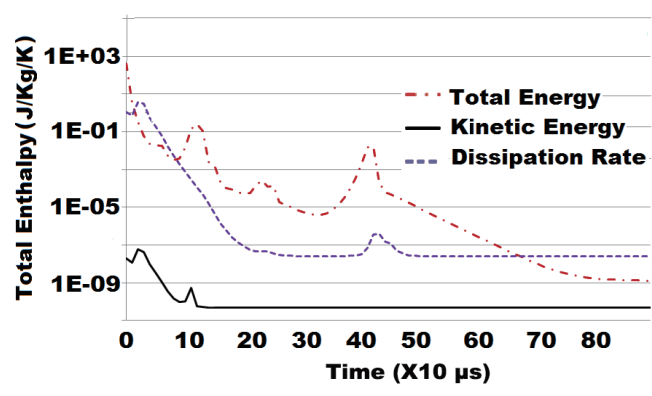

(b)

Fig. 10. (Color online) Gas total energy responses of step-input acceleration for cases applying floating structure and hemicylindrical chamber with (a) $\mathrm{CO}_{2}$ and (b) xenon. 


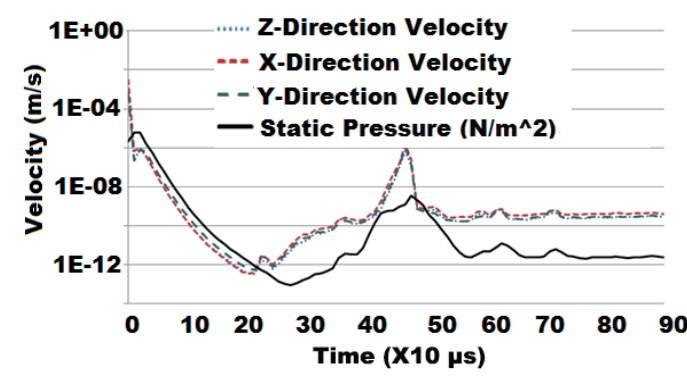

(a)

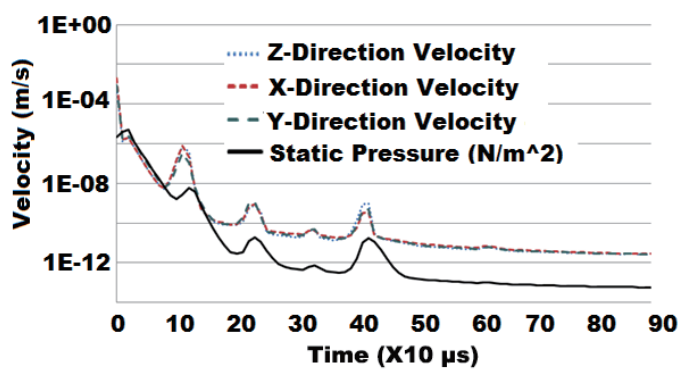

(b)

Fig. 11. (Color online) Gas velocity responses of step-input acceleration for cases applying floating structure and hemicylindrical chamber with (a) $\mathrm{CO}_{2}$ and (b) xenon.

Table 1

Response time comparison of gas total energy and velocity by using floating structure for rectangular and hemicylindrical chambers with $\mathrm{CO}_{2}$ and xenon.

\begin{tabular}{lcc}
\hline Chamber type & $\mathrm{CO}_{2}(\mu \mathrm{s})$ & Xenon $(\mu \mathrm{s})$ \\
\hline Rectangular & 910 & 610 \\
Hemicylindrical & 810 & 500 \\
\hline
\end{tabular}

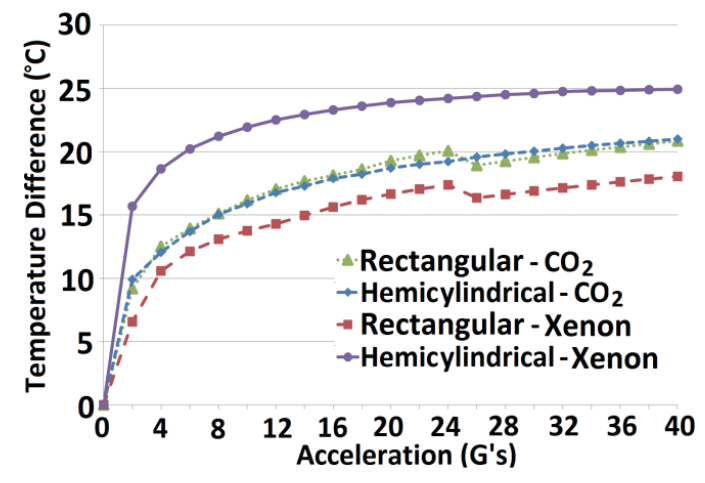

(a)

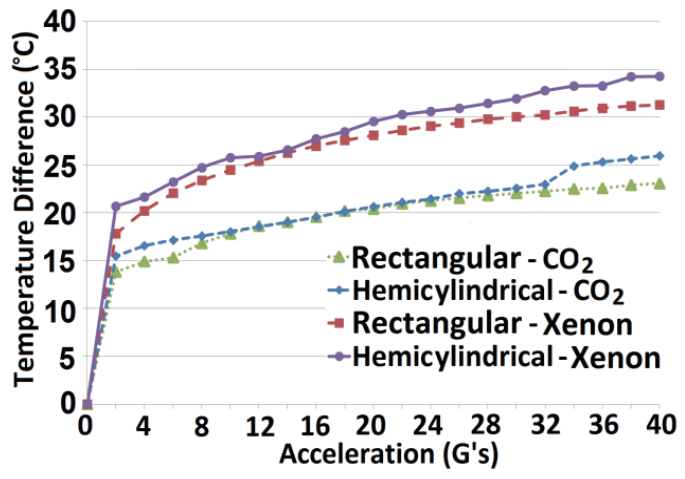

(b)

Fig. 12. (Color online) Sensitivity curves for nonfloating structures applying hemicylindrical and rectangular chambers filled with $\mathrm{CO}_{2}$ or xenon. (a) Without stacking layer. (b) With stacking layer. 


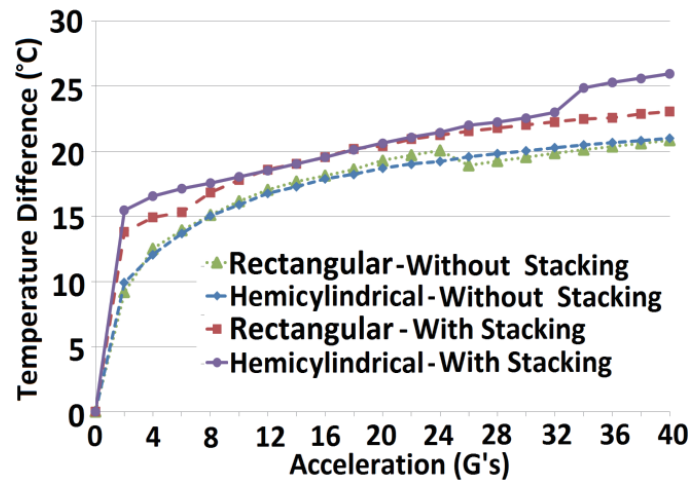

(a)

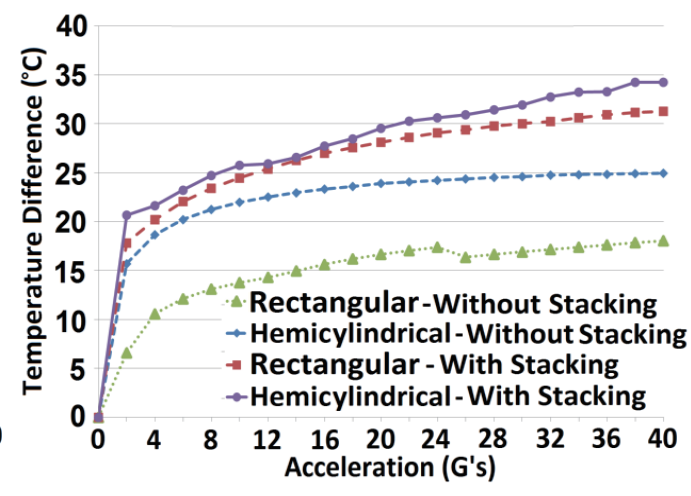

(b)

Fig. 13. (Color online) Sensitivity curves for nonfloating structures applying hemicylindrical and rectangular chambers with/without stacking layer. (a) $\mathrm{CO}_{2}$. (b) Xenon.

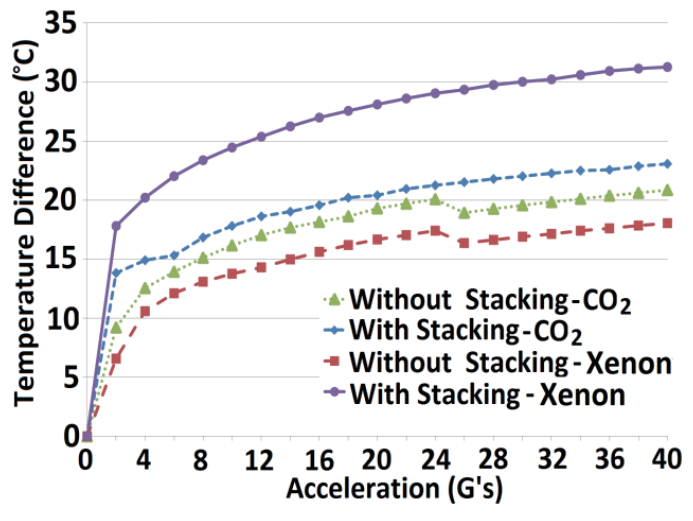

(a)

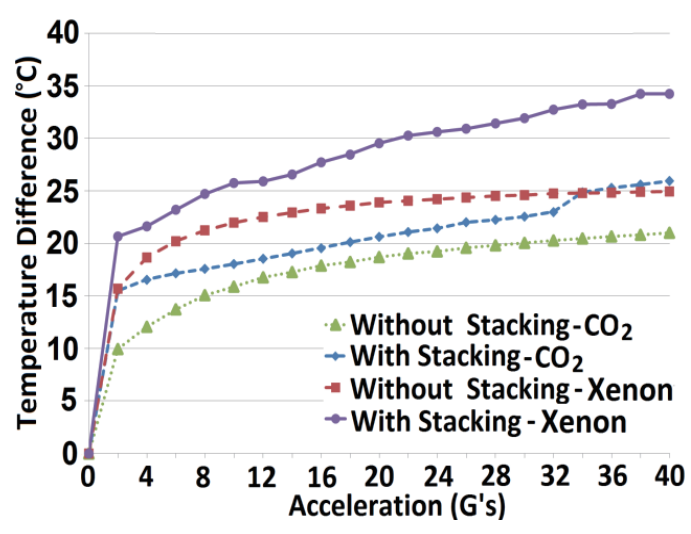

(b)

Fig. 14. (Color online) Sensitivity curves for nonfloating structure with/without stacking layer, and filled by $\mathrm{CO}_{2}$ or xenon. (a) Rectangular chamber. (b) Hemicylindrical chamber.

Table 2

Sensitivity comparison by using nonfloating structure for rectangular and hemicylindrical chambers with $\mathrm{CO}_{2}$ and xenon.

\begin{tabular}{lccc}
\hline Chamber type & Stacking type & $\mathrm{CO}_{2}\left({ }^{\circ} \mathrm{C} / \mathrm{G}\right)$ & Xenon $\left({ }^{\circ} \mathrm{C} / \mathrm{G}\right)$ \\
\hline \multirow{2}{*}{ Rectangular } & With stacking & 0.11 & 0.182 \\
& Without stacking & Nonlinear & Nonlinear \\
\hline \multirow{2}{*}{ Hemicylindrical } & With stacking & Nonlinear & 0.227 \\
& Without stacking & 0.114 & 0.045 \\
\hline
\end{tabular}




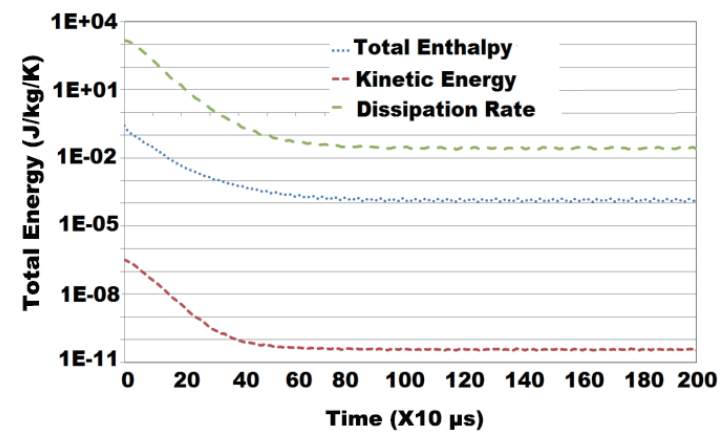

(a)

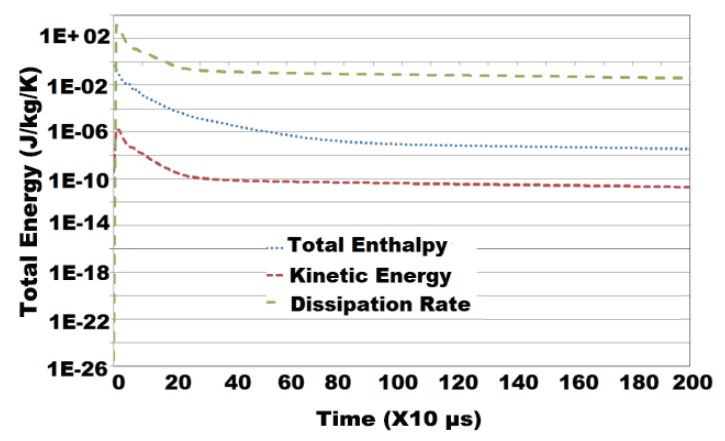

(b)

Fig. 15. (Color online) Gas total energy responses of step-input acceleration for cases applying nonfloating structure, stacking layer, and rectangular chamber. (a) $\mathrm{CO}_{2}$. (b) Xenon.

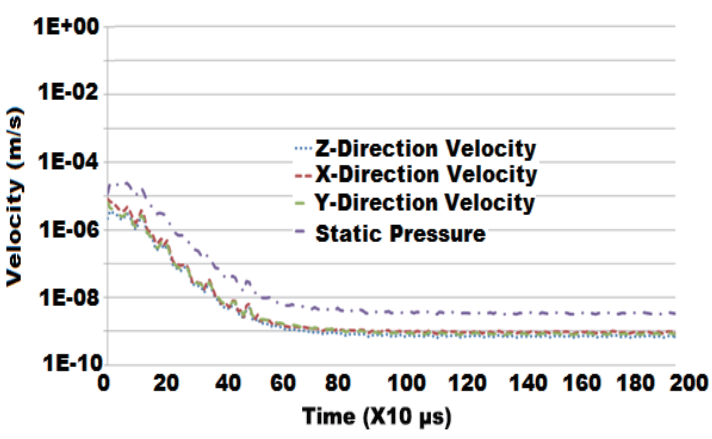

(a)

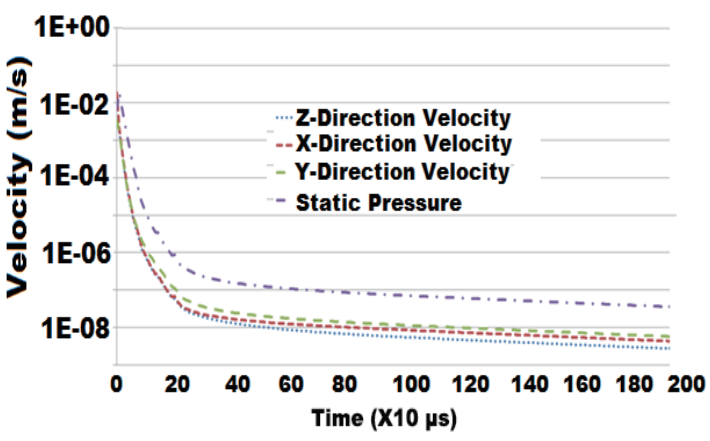

(b)

Fig. 16. (Color online) Gas velocity response curves of step-input acceleration for cases applying nonfloating structure, stacking layer, and rectangular chamber. (a) $\mathrm{CO}_{2}$. (b) Xenon.

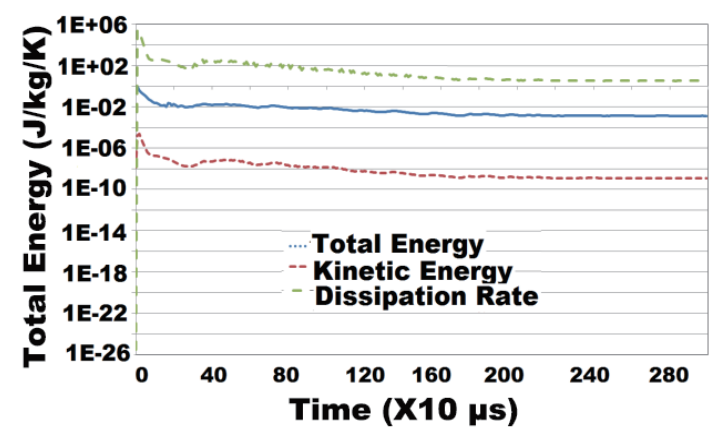

(a)

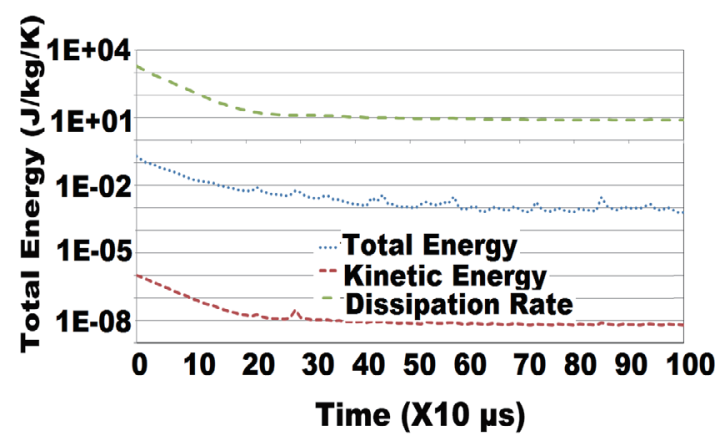

(b)

Fig. 17. (Color online) Gas total energy responses of step-input acceleration for cases applying nonfloating structure, stacking layer, and hemicylindrical chamber. (a) $\mathrm{CO}_{2}$. (b) Xenon. 


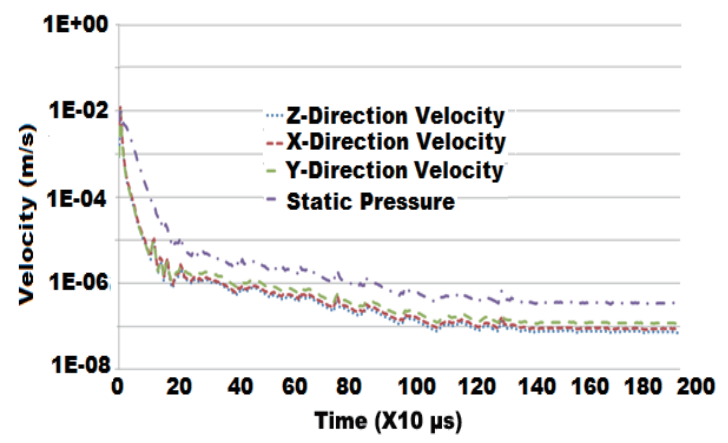

(a)

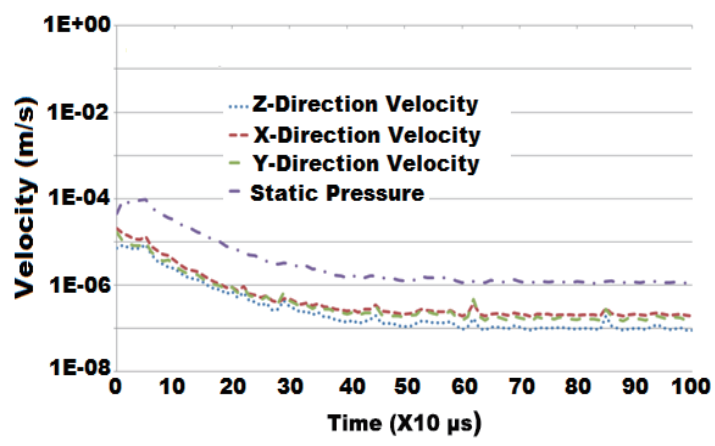

(b)

Fig. 18. (Color online) Gas velocity response curves of step-input acceleration for cases applying nonfloating structure, stacking layer, and hemicylindrical chamber. (a) $\mathrm{CO}_{2}$. (b) Xenon.

Table 3

Response time comparison of gas total energy and velocity by using nonfloating structure and stacking layer for rectangular and hemicylindrical chambers with $\mathrm{CO}_{2}$ and xenon.

\begin{tabular}{lcc}
\hline Chamber type & $\mathrm{CO}_{2}(\mu \mathrm{s})$ & Xenon $(\mu \mathrm{s})$ \\
\hline Rectangular & 600 & 400 \\
Hemicylindrical & 500 & 310 \\
\hline
\end{tabular}

\section{Conclusions}

The major contributions are summarized as follows.

(1) It is a new idea to make both heater and temperature sensors above a stacking material on a plastic substrate without using the traditional floating structure; thus, the cost of the former nonfloating structure can be reduced. Besides, the thermal isolation and power dissipation are better and lower than those by using the previous silicon. The chamber is filled with inert xenon gas; thus, the oxidizing effects of the heater and thermal sensors produced by the traditional $\mathrm{CO}_{2}$ or air can be avoided.

(2) Moreover, it is a new idea to integrate the RFID tag with the thermal convection accelerometer on the plastic substrate, and one can make it become a wireless acceleration sensor.

(3) Comparisons with the conventional thermal convection accelerometer of the rectangular chamber and filled with $\mathrm{CO}_{2}$ are also made. The sensitivity $\left(0.227^{\circ} \mathrm{C} /\right.$ $\mathrm{G})$ for the new case by using the hemicylindrical chamber and nonfloating structure with xenon gas and stacking layer is better and without the nonlinear effect in larger accelerations.

(4) Note that for the floating and nonfloating structures, the response times by using either the hemicylindrical chamber and/or xenon gas are also faster than the conventional ones $(910$ and $600 \mu \mathrm{s})$ with the rectangular chamber and $\mathrm{CO}_{2}$. The quickest one (310 
$\mu$ ) is the case applying the proposed ideas by using the hemicylindrical chamber and xenon gas. Moreover, they are also faster than those of the floating cases.

\section{Acknowledgements}

This work was supported by the National Science Council under grant Nos. NSC 101-2622-E-216-001-CC3, 101-2221-E-216-006-MY2, 101-2221-E-216-019, and 102-2622-E-216-002-CC2, and the National Center of High-Performance Computing (NCHC) by providing computer time and facilities for simulating the ESI-CFD+ software package.

\section{References}

1 S. Kobayashi, Y. Watanabe, S. Kanauchi, I. Nakagawa, E. Suganuma and M. Esashi: 8th International Conference on Solid-State Sensors and Actuators (1995) p. 554.

2 K. M. Liao, R. Chen and B. C. S. Chou: Sens. Actuators, A 130-131 (2006) 282.

3 L. C. Spangler and C. J. Kemp: Sens. Actuators, A 54 (1996) 523.

4 L. Lin, R. T. Howe and A. P. Pisano: IEEE J. Microelectromech. Syst. 7 (1998) 286.

5 J. Bahari and A. M. Leung: J. Micromech. Microeng. 21 (2011) 1.

6 A. Petropoulosa, A. Moschosa, S. Athineosa and G. Kaltsas: Procedia Eng. 25 (2011) 643.

7 X. B. Luo, Z. X. Li, Z. Y. Guo and Y. J. Yang: J. Micromech. Microeng. 11 (2001) 504.

8 G. Piazza and P. Stephanou: Micromechanical Thermo-Fluidic Single-Axis Yaw Rate Sensor (University of California Berkeley, USA, 2002).

9 F. Peluso, D. Castagnolo and C. Albanese: Microgravity Sci. Technol. 13 (2002) 41.

10 B. Alain, R. Alain, V. Bernard and G. Alain: European Patent EP. 1550874 (2010).

11 R. Dao, D. E. Morgan, H. H. Kries and D. M. Bachelder: U.S. Patent No. 5581034 (1996).

12 J. Courteaud, N. Crespy, P. Combette, B. Sorli and A. Giani: Sens. Actuators, A 47 (2008) 75.

13 J. M. Lin and C. H. Lin: 2013 International Conference on Computer, Networks and Communication Engineering (2013) p. 569.

14 F. Khoshnoud and C. W. de Silva: IEEE Instrum. Meas. Mag. 15 (2012) 14.

15 A. Garraud, A. Giani, P. Combette, B. Charlot and M. Richard: Sens. Actuators, A 170 (2011) 44.

16 Y. Zhao, A. P. Brokaw, M. E. Rebeschini, A. M. Leung, G. P. Pucci and A. Dribinsky: U.S. Patent No. 6795752 B1 (2004).

17 Y. Zhao, A. Leung, M. E. Rebeschini, G. P. Pucci, Dribinsky and B. A. Y. Cai: U.S. Patent No. 7305881 B2 (2007).

18 T. R. Hsu: MEMS \& Microsystems (McGraw-Hill Companies Inc., Boston, USA, 2002).

19 A. A. Rekik, F. Azaïs, N. Dumas, F. Mailly and P. Nouet: J. Electron. Test. 27 (2011) 411.

20 A. Dribinsky, G. P. Pucci, Y. Cai, M. Varghese, G. J. O’Brien, Y. Zhao and Y. Y. Cai: U.S. Patent No. 7862229 B2 (2011).

21 J. Dido, P. Loisel and A. Renault: U.S. Patent No. 7426862 B2 (2008).

22 U. A. Dauderstadt, P. H. S. de Vries, R. Hiratsuka, J. G. Korvink, P. M. Sarro, H. Baltes and S. Middelhoek: Sens. Actuators, A 55 (1996) 3.

23 U. A. Dauderstadt, P. M. Sarro and P. J. French: Solid State Sens. Actuators 66 (2008) 244.

24 Y. F. Ren and K. X. Zheng: J. Digital Content Technol. Appl. 4 (2010) 209.

25 A. H. Ma and A. M. Leung: IEEE Sens. (2008) 1492.

26 G. Daia, M. Li, X. P. He, L. M. Du, B. B. Shao and W. Su: Sens. Actuators, A 172 (2011) 369. 
27 L. A. Rocha, C. S. Silva, M. F. Cerqueira, J. F. Ribeiro, L. M. Goncalves, A. J. Pontes and J. C. Viana: Procedia Eng. 25 (2011) 607.

28 Y. Hua, Z. Li and H. Xaio: U.S. Patent No. 8011226 B2 (2011).

29 R. Zhu, H. Ding, Y. Su and Y. Yang: Sensors 10 (2010) 8304.

30 V. T. Dau, D. V. Dao, T. Shiozawa, H. Kumagai and S. Sugiyama: J. Micromech. Microeng. $16(2006) 1301$.

31 A. Ya'akobovitz and S. Krylov: IEEE J. Sens. 10 (2010) 1311.

32 Y. L. Chen and X. Z. Shi: Int. J. Eng. Technol. Innovation 3 (2012) 216. 